\title{
Assay for Transposase-Accessible Chromatin-Sequencing Using Xenopus Embryos
}

\author{
Ann Rose Bright ${ }^{1}$ and Gert Jan C. Veenstra ${ }^{1,2}$ \\ ${ }^{1}$ Radboud University, Department of Molecular Developmental Biology, Faculty of Science, Radboud Institute for \\ Molecular Life Sciences, Nijmegen 6500 HB, The Netherlands
}

\begin{abstract}
The DNA of eukaryotic genomes is packaged into chromatin by nucleosomes. This not only compacts the DNA but also plays a central role in gene regulation and establishment of cellular identity during development. Because of this packaging, the DNA is relatively inaccessible to nucleoplasmic factors; however, regulatory elements such as promoters, enhancers, and insulators are largely kept nucleosome-free. The assay for transposase-accessible chromatin (ATAC-seq) can be used to identify genomic locations of "open" chromatin, footprints of DNA-binding proteins, and positioned nucleosomes. It therefore is a powerful tool for unraveling the dynamic regulatory landscape of chromatin. The method exploits the action of hyperactive prokaryotic Tn5-transposase, which preferentially cuts DNA in accessible chromatin and tags the sites with sequencing adaptors. Here we describe an ATACseq protocol for use with Xenopus tropicalis embryos.
\end{abstract}

It is essential that you consult the appropriate Material Safety Data Sheets and your institution's Environmental Health and Safety Office for proper handling of equipment and hazardous materials used in this protocol.

RECIPES: Please see the end of this protocol for recipes indicated by $<R>$. Additional recipes can be found online at http://cshprotocols.cshlp.org/site/recipes.

Reagents

Cysteine (3\%)

Prepare 3\% cysteine solution in $0.1 \times \mathrm{MMR}$. Adjust to $\mathrm{pH} 7.8$ using $\mathrm{NaOH}$.

HiFi HotStart ReadyMix PCR Kit (KAPA KK2602)

Lysis buffer for Xenopus $<\mathrm{R}>$ (ice-cold)

Marc's Modified Ringer's (MMR) solution $(1 \times)<\mathrm{R}>$

MinElute PCR Purification Kit (including Elution Buffer) (QIAgen 28004)

Nextera DNA Library Preparation Kit (including $2 \times$ TD Buffer and Tn5 Transposase) (Illumina

FC-121-1030)

Nextera Index Kit (Illumina FC-121-1011)

qPCR primers for performing quality checks (see Discussion and Table 1)

${ }^{2}$ Correspondence: g.veenstra@science.ru.nl

From the Xenopus collection, edited by Hazel L. Sive.

(C) 2019 Cold Spring Harbor Laboratory Press

Cite this protocol as Cold Spring Harb Protoc; doi:10.1101/pdb.prot098327 
A.R. Bright and G.J.C. Veenstra

TABLE 1. Primer sequences spanning hypersensitive, nonhypersensitive, and mitochondrial regions

\begin{tabular}{|c|c|c|}
\hline Genomic location $^{\mathrm{a}}$ & Forward sequence & Reverse sequence \\
\hline \multicolumn{3}{|l|}{ Hypersensitive region } \\
\hline Chr02:86683349-86683371 & GCAGAGGTGAGTATGGGATGG & AAAAGCAGGCCAGTAAGCCA \\
\hline Chr05:14131176-14131196 & AGCAGGAGGGTCATGTCAAC & GTGCGTTTAGGGCTATCGAG \\
\hline Chr01:141442069-141442089 & GCAGAAGGGGAGGAGAACT & АACTGCAAGCСТGCTAAGGT \\
\hline Chr05:118265078-118265098 & GAATAGGGCAACACAAGGCT & TCTTTTCAAАCACСАСССGC \\
\hline \multicolumn{3}{|l|}{ Nonhypersensitive region } \\
\hline Chr02:5242998-5243018 & САTTCCCTACTGGGCTGGGT & CACACTGCTGGCCATCGTT \\
\hline Chr05:7602266-7602286 & TTTCAGTCCCGCAGATTTTC & TACAATGGCCCAATCAAAGC \\
\hline \multicolumn{3}{|l|}{ Mitochondrial region } \\
\hline mitochondrion:11795-11815 & ССТССАССТСАТСССТАТСА & CCAGCGGAGAGACTGTTTTC \\
\hline mitochondrion:8777-8797 & GTCGCAGСССТTCTACTCAC & ACTGGAGGAGTGTGGTGTCC \\
\hline mitochondrion:8918-8938 & CCGAGCCTACTTCACСТCAG & AGAAGAGTTGGCAAGGACGA \\
\hline
\end{tabular}

${ }^{\mathrm{a}} \mathrm{Genomic}$ positions refer to $X$. tropicalis genome assembly v9.0.

SYBR Green I nucleic acid gel stain (Life Technologies, S7563)

Prepare $100 \times$ SYBR Green I solution by mixing $1 \mu \mathrm{L}$ of 10,000 $\times$ SYBR Green I with $99 \mu \mathrm{L}$ of Elution Buffer $(10 \mathrm{~mm}$ Tris-Cl, $\mathrm{pH}$ 8).

Xenopus tropicalis embryos

Equipment

Bioanalyzer

Heat block at $37^{\circ} \mathrm{C}$

Heratherm incubator (Thermo Scientific)

Microcentrifuge, cooling (Thermo Scientific)

Microcentrifuge tubes $(1.5-\mathrm{mL})$

PCR tubes $(0.2-\mathrm{mL})$

Petri dishes (100-mM, plastic)

Real-time quantitative polymerase chain reaction (qPCR) system

Thermal cycler (Bio-Rad T100)

METHOD

This protocol is adapted from the ATAC-seq method originally described by Buenrostro et al. (2013). For further reading about chromatin structure and development, see Perino and Veenstra (2016) and Boyle et al. (2008).

Preparing Lysates

Generally it is recommended to use fresh material for preparation of lysates. ATAC libraries can be prepared using frozen embryos (see Step 4); however, the enrichment of signal in accessible chromatin tends to be lower compared to libraries prepared with fresh material.

1. Collect $X$. tropicalis embryos in a Petri dish. Dejelly the embryos using $3 \%$ cysteine.

2. Rinse the embryos in $\mathrm{H}_{2} \mathrm{O}$ to remove the cysteine. Raise the embryos in $0.1 \times$ MMR until the desired stage is attained.

3. Transfer embryos in a number equivalent to $25,000-75,000$ cells to a $1.5-\mathrm{mL}$ microcentrifuge tube for further processing.

For example, for stage 12 embryos ( 30,000 cells/embryo) we have used two embryos per reaction. More generally, the efficiency of the reaction depends on the number of cells relative to the amount of Tn5 transposase. For best results, we have found titration of the embryo lysate with a constant amount of Tn5 to be useful. 
4. Remove the excess MMR solution and then add $10 \mu \mathrm{L}$ of ice-cold lysis buffer to the embryos. Pipette the embryos up and down with a clipped P20 pipette tip until a homogenized lysate is formed.

Clipped pipette tips help to prevent shearing of nuclei and chromatin.

Embryos can be snap-frozen after removal of excess MMR solution and stored at $-80^{\circ} \mathrm{C}$. For subsequent ATAC-seq, the samples are thawed quickly by addition of lysis buffer followed by pipetting up and down.

5. Place the lysate on ice for $5 \mathrm{~min}$ to ensure proper lysis, and then proceed directly with the transposition reaction (Step 6).

Performing Transposition

6. Combine the following to prepare the transposition reaction mix. Mix gently without vortexing.

\begin{tabular}{lr}
\hline Reagent & Amount \\
\hline Cell lysate from Step 5 & $10 \mu \mathrm{L}$ \\
2× TD Buffer & $25 \mu \mathrm{L}$ \\
Tn5 Transposase & $2.5 \mu \mathrm{L}$ \\
Nuclease-free $\mathrm{H}_{2} \mathrm{O}$ & $12.5 \mu \mathrm{L}$ \\
Total & $50 \mu \mathrm{L}$ \\
\hline
\end{tabular}

7. Incubate the reaction mix for $30 \mathrm{~min}$ at $37^{\circ} \mathrm{C}$.

8. Immediately following transposition, purify the DNA from the reaction mix using a MinElute kit. Elute the transposed DNA in $10 \mu \mathrm{L}$ of Elution Buffer (10 mM Tris buffer, $\mathrm{pH} 8$ ).

Purified samples can be stored at $-20^{\circ} \mathrm{C}$.

Performing PCR Amplification

9. Combine the following in a PCR tube to prepare the PCR reaction mix. Mix gently by pipetting.

\begin{tabular}{lc}
\hline Reagent & Amount \\
\hline Transposed DNA from Step 8 & $10 \mu \mathrm{L}$ \\
Nuclease-free $\mathrm{H}_{2} \mathrm{O}$ & $10 \mu \mathrm{L}$ \\
$25 \mu \mathrm{M}$ Index 1 (Nextera Index Kit) & $2.5 \mu \mathrm{L}$ \\
$25 \mu \mathrm{M}$ Index 2 (Nextera Index Kit) & $2.5 \mu \mathrm{L}$ \\
Kapa Hifi PCR Master mix & $25 \mu \mathrm{L}$ \\
Total & $50 \mu \mathrm{L}$ \\
\hline
\end{tabular}

10. Amplify the transposed DNA using the following cycling program.

1

2

3

4

5

6

7

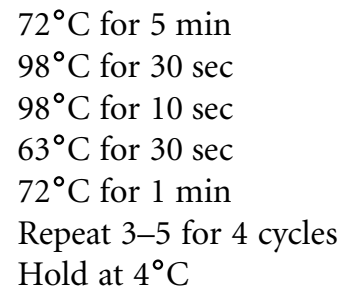

$72^{\circ} \mathrm{C}$ for $5 \mathrm{~min}$ $98^{\circ} \mathrm{C}$ for $30 \mathrm{sec}$ $98^{\circ} \mathrm{C}$ for $10 \mathrm{sec}$ $63^{\circ} \mathrm{C}$ for $30 \mathrm{sec}$ $72^{\circ} \mathrm{C}$ for $1 \mathrm{~min}$ Repeat 3-5 for 4 cycles Hold at $4^{\circ} \mathrm{C}$

11. Determine the number of additional cycles needed for the amplification of the library using $\mathrm{qPCR}$ as follows. 
A.R. Bright and G.J.C. Veenstra

i. Prepare the qPCR reaction mix.

\begin{tabular}{lr}
\hline Reagent & Amount \\
\hline Amplified DNA from Step 10 & $5 \mu \mathrm{L}$ \\
Nuclease-free $\mathrm{H}_{2} \mathrm{O}$ & $4.44 \mu \mathrm{L}$ \\
$25 \mu$ M Index 1 (Nextera Index Kit) & $0.25 \mu \mathrm{L}$ \\
$25 \mu$ Index 2 (Nextera Index Kit) & $0.25 \mu \mathrm{L}$ \\
100× SYBR Green I & $0.06 \mu \mathrm{L}$ \\
PCR Master Mix (HiFi HotStart ReadyMix) & $5 \mu \mathrm{L}$ \\
Total & $15 \mu \mathrm{L}$ \\
\hline
\end{tabular}

ii. Use the following cycling program to perform qPCR.

$\begin{array}{ll}1 & 98^{\circ} \mathrm{C} \text { for } 30 \mathrm{sec} \\ 2 & 98^{\circ} \mathrm{C} \text { for } 10 \mathrm{sec} \\ 3 & 63^{\circ} \mathrm{C} \text { for } 30 \mathrm{sec} \\ 4 & 72^{\circ} \mathrm{C} \text { for } 1 \mathrm{~min} \\ 5 & \text { Repeat } 2-4 \text { for } 19 \text { cycles } \\ 6 & \text { Hold at } 4^{\circ} \mathrm{C}\end{array}$

iii. Calculate the number of additional cycles $(x)$ needed for the amplification of the library by plotting the resulting fluorescence versus the number of cycles and setting the threshold at one-fourth of maximum fluorescence.

This corresponds to the number of cycles needed to reach the beginning of exponential increase of fluorescence (Buenrostro et al. 2013).

12. Amplify the remaining reaction mix from Step 10 using the following cycling program and the cycle number $(x)$ calculated in Step 11.iii.
1
2
$98^{\circ} \mathrm{C}$ for $30 \mathrm{sec}$
$98^{\circ} \mathrm{C}$ for $10 \mathrm{sec}$
$63^{\circ} \mathrm{C}$ for $30 \mathrm{sec}$
$72^{\circ} \mathrm{C}$ for $1 \mathrm{~min}$
4
Repeat 2-4 for $x$ cycles
6 Hold at $4^{\circ} \mathrm{C}$

13. Purify the amplified product using the MinElute kit. Elute in $20 \mu \mathrm{L}$ of Elution Buffer.

Purified samples can be stored at $-20^{\circ} \mathrm{C}$.

14. Perform quality checks of signal-to-noise ratio, mitochondrial contamination and sample profile (fragment size distribution) before sequencing and analysis (see Discussion and Table 1).

See Troubleshooting.

Problem (Step 14): Cells are not adequately lysed, leading to low quality samples.

Solution: Prepare and test lysis buffer containing different concentrations of IGEPAL CA-630 (0.5\%, $0.1 \%, 0.05 \%$, and $0.025 \%)$.

Problem (Step 14): Large fragments (700- to 1000-bp) are present in the library due to inadequate (nonspecific) transposition, and/or low enrichment of positive regions over negative regions in qPCR quantification. 
Solution: To optimize the efficiency of specific transposition, do a titration with different concentrations of Tn5 (or use different amounts of embryo lysate with a fixed amount of Tn5). If large fragments ( $>1 \mathrm{~kb}$, nonspecific transposition) are observed in the library, in addition to the small sizes (transposition in accessible regions), size-selecting the library for 100- to 700-bp fragments (including primer sequence) might help to enhance library quality. The Select-a-Size DNA Clean \& Concentrator kit (Zymo Research D4080) can be used for purifying out the desired library size.

\section{DISCUSSION}

\section{Performing Quality Checks}

\section{Signal-to-Noise Ratio}

The signal-to-noise ratio can be determined by performing qPCR using primers spanning hypersensitive and nonhypersensitive regions. We have designed primers spanning H3K4me3-positive promoters and Ep300-positive enhancers for positive regions and for regions without any of the wellknown histone modifications and genes nearby as negative (relatively inaccessible) controls (Table 1). Good quality samples have $\geq 10$-fold enrichment for positive regions against negative regions.

\section{Mitochondrial Contamination}

The abundance of mitochondrial DNA in the accessible fraction is one of the well-known limitations of the technique: The mitochondrial DNA reduces the coverage of genomic DNA when the ATAC library is sequenced. The extent of mitochondrial contamination in the library can be quantified by qPCR, using primers spanning mitochondrial regions (Table 1). The percentage of mitochondrial reads may vary across samples; it can range from $\sim 10 \%-50 \%$ of sequenced reads.

\section{Sample Profile}

The libraries generated using ATAC-seq usually have a highly diverse fragment size distribution. Samples containing excessive large fragments $(>1 \mathrm{~kb})$ are relatively hard to quantify and result in reduced clustering efficiencies when sequenced (Buenrostro et al. 2013). Thus, this information is a good indicator of sample quality and can be checked using a Bioanalyzer.

ATAC-Sequencing and Analysis

\section{Paired-End or Single-End Sequencing}

The fragments generated in ATAC-seq are of different lengths. The small ones (50-150 bp, excluding primer sequences) correspond to nucleosome-free hypersensitive regions, and the longer ones (200$500 \mathrm{bp}$ ) correspond to open regions that are separated by one or more nucleosomes (mostly doublecut fragments from the edges of the accessible regions). Paired-end sequencing is advantageous over single-end sequencing as it gives us the information to determine both the pattern of accessibility within open regions and the positions of flanking nucleosomes based on fragment length. Paired-end sequencing of $2 \times 40 \mathrm{bp}$ is sufficient to map the reads to the genome.

\section{Sequencing Depth}

The depth to which the sample needs to be sequenced depends on the information to be obtained. Information on chromatin accessibility and nucleosome positioning can be attained through $\sim 30-40$ million mapped reads for samples with decent enrichments of accessible chromatin and low mitochondrial DNA contamination (Fig. 1). For further analysis, it is advised in most cases to take only the nonduplicate (only one read per genomic position) and uniquely mapped (mapped to unique parts of the genome) reads. A good data set typically has at least 25 million nonduplicate, nonmitochondrial 
A.R. Bright and G.J.C. Veenstra

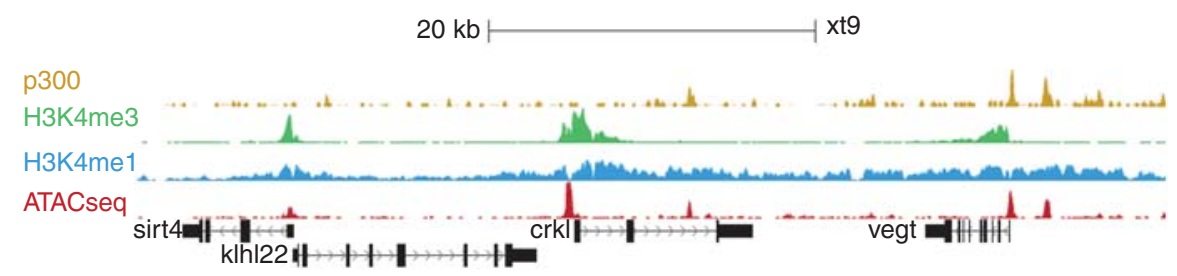

FIGURE 1. ChIP-seq and ATAC-seq profiles surrounding the vegt locus in stage 12 (late gastrula) X. tropicalis embryos.

aligned (mapped) reads per replicate. For in-depth analysis of transcription factor footprints, at least 100 million mapped reads are necessary.

\section{Replicates}

The most accessible sites will be consistent across replicates, so for a global analysis of chromatin accessibility two replicates often suffice; for high confidence analysis of weakly accessible regions and to explicitly account for biological variation, a larger number of replicates may be necessary.

\section{Sample Analysis Pipeline}

Single-end or paired-end reads can be mapped to the genome using BWA-MEM (Li and Durbin 2009) followed by filtering steps to remove duplicates using Picard's Mark Duplicates (http://broadinstitute. github.io/picard/) and unmapped reads. Shift the reads +4 bp for the + strand and -5 bp for the strand to account for the properties of the accessible site relative to the read; this is primarily relevant when attempting to do high resolution transcription factor footprinting analysis. Peak calling can be done using MACS2 (Zhang et al. 2008). The processed samples can be used for further analyses such as differential chromatin accessibility, clustering and Motif enrichment. In the case of footprint identification, the sequence bias of Tn5 should be controlled using naked genomic DNA (Lu et al. 2017).

Lysis Buffer for Xenopus

$10 \mathrm{~mm}$ Tris- $\mathrm{HCl}(\mathrm{pH} 7.4)$

$10 \mathrm{~mm} \mathrm{NaCl}$

$3 \mathrm{mM} \mathrm{MgCl}_{2}$

$0.1 \%$ IGEPAL CA-630

Store for up to $1 \mathrm{wk}$ at $4^{\circ} \mathrm{C}$.

Marc's Modified Ringer's (MMR) Solution (1x)

$0.1 \mathrm{M} \mathrm{NaCl}$

$0.1 \mathrm{~mm}$ EDTA

$1 \mathrm{mM} \mathrm{MgSO}_{4}$

$2 \mathrm{mM} \mathrm{CaCl}_{2}$

$2 \mathrm{~mm} \mathrm{KCl}$

$5 \mathrm{~mm}$ HEPES (pH 7.8)

Autoclave. Store for up to $6 \mathrm{mo}$ at room temperature. 


\section{REFERENCES}

Boyle AP, Davis S, Shulha HP, Meltzer P, Margulies EH, Weng Z, Furey TS, Crawford GE. 2008. High-resolution mapping and characterization of open chromatin across the genome. Cell 132: 311-322.

Buenrostro JD, Giresi PG, Zaba LC, Chang HY, Greenleaf WJ. 2013. Transposition of native chromatin for fast and sensitive epigenomic profiling of open chromatin, DNA-binding proteins and nucleosome position. Nat Methods 10: 1213-1218.

Li H, Durbin R. 2009. Fast and accurate short read alignment with BurrowsWheeler transform. Bioinformatics 25: 1754-1760.
Lu Z, Hofmeister BT, Vollmers C, Dubois RM, Schmitz RJ. 2017. Combining ATAC-seq with nuclei sorting for discovery of cis-regulatory regions in plant genomes. Nucleic Acids Res 45: e41.

Perino M, Veenstra GJ. 2016. Chromatin control of developmental dynamics and plasticity. Dev Cell 38: 610-620.

Zhang Y, Liu T, Meyer CA, Eeckhoute J, Johnson DS, Bernstein BE, Nusbaum C, Myers RM, Brown M, Li W, et al. 2008. Model-based analysis of ChIP-Seq (MACS). Genome Biol 9: R137. 


\section{Assay for Transposase-Accessible Chromatin-Sequencing Using Xenopus Embryos}

Ann Rose Bright and Gert Jan C. Veenstra

Cold Spring Harb Protoc; doi: 10.1101/pdb.prot098327 originally published online July 24, 2018

\begin{tabular}{rc}
$\begin{array}{r}\text { Email Alerting } \\
\text { Service }\end{array}$ & Receive free email alerts when new articles cite this article - click here. \\
\hline $\begin{array}{c}\text { Subject } \\
\text { Categories }\end{array}$ & Browse articles on similar topics from Cold Spring Harbor Protocols. \\
& Developmental Biology (728 articles) \\
& DNA Sequencing (96 articles) \\
DNA:Protein Interactions (74 articles) & Genome Analysis (191 articles) \\
& Genomic Libraries (66 articles) \\
& Libraries (147 articles) \\
& Molecular Biology, general (1293 articles) \\
& Xenopus (210 articles) \\
\hline
\end{tabular}

